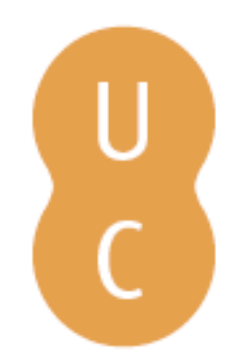

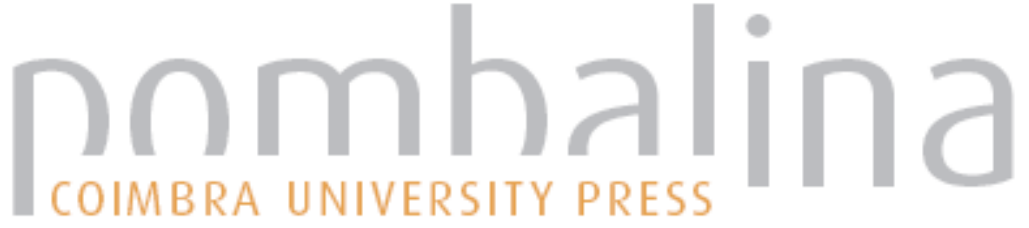

\section{Las unidades léxicas y la enseñanza del léxico a extranjeros}

Autor(es): $\quad$ Higueras García, Marta

Publicado por: Imprensa da Universidade de Coimbra

URL

persistente: URI:http://hdl.handle.net/10316.2/41005

DOI: $\quad$ DOI:http://dx.doi.org/10.14195/978989261231-7_2

Accessed : $\quad$ 26-Apr-2023 14:13:39

A navegação consulta e descarregamento dos títulos inseridos nas Bibliotecas Digitais UC Digitalis, UC Pombalina e UC Impactum, pressupõem a aceitação plena e sem reservas dos Termos e Condições de Uso destas Bibliotecas Digitais, disponíveis em https://digitalis.uc.pt/pt-pt/termos.

Conforme exposto nos referidos Termos e Condições de Uso, o descarregamento de títulos de acesso restrito requer uma licença válida de autorização devendo o utilizador aceder ao(s) documento(s) a partir de um endereço de IP da instituição detentora da supramencionada licença.

Ao utilizador é apenas permitido o descarregamento para uso pessoal, pelo que o emprego do(s) título(s) descarregado(s) para outro fim, designadamente comercial, carece de autorização do respetivo autor ou editor da obra.

Na medida em que todas as obras da UC Digitalis se encontram protegidas pelo Código do Direito de Autor e Direitos Conexos e demais legislação aplicável, toda a cópia, parcial ou total, deste documento, nos casos em que é legalmente admitida, deverá conter ou fazer-se acompanhar por este aviso. 


\section{ENSEÑAR ESPAÑOL EN LA ACTUALIDAD \\ CONTRIBUCIONES DIDÁCTICAS}

MARÍA LUISA' AZNAR JUAN ELENA GAMAZO CARRETERO II.

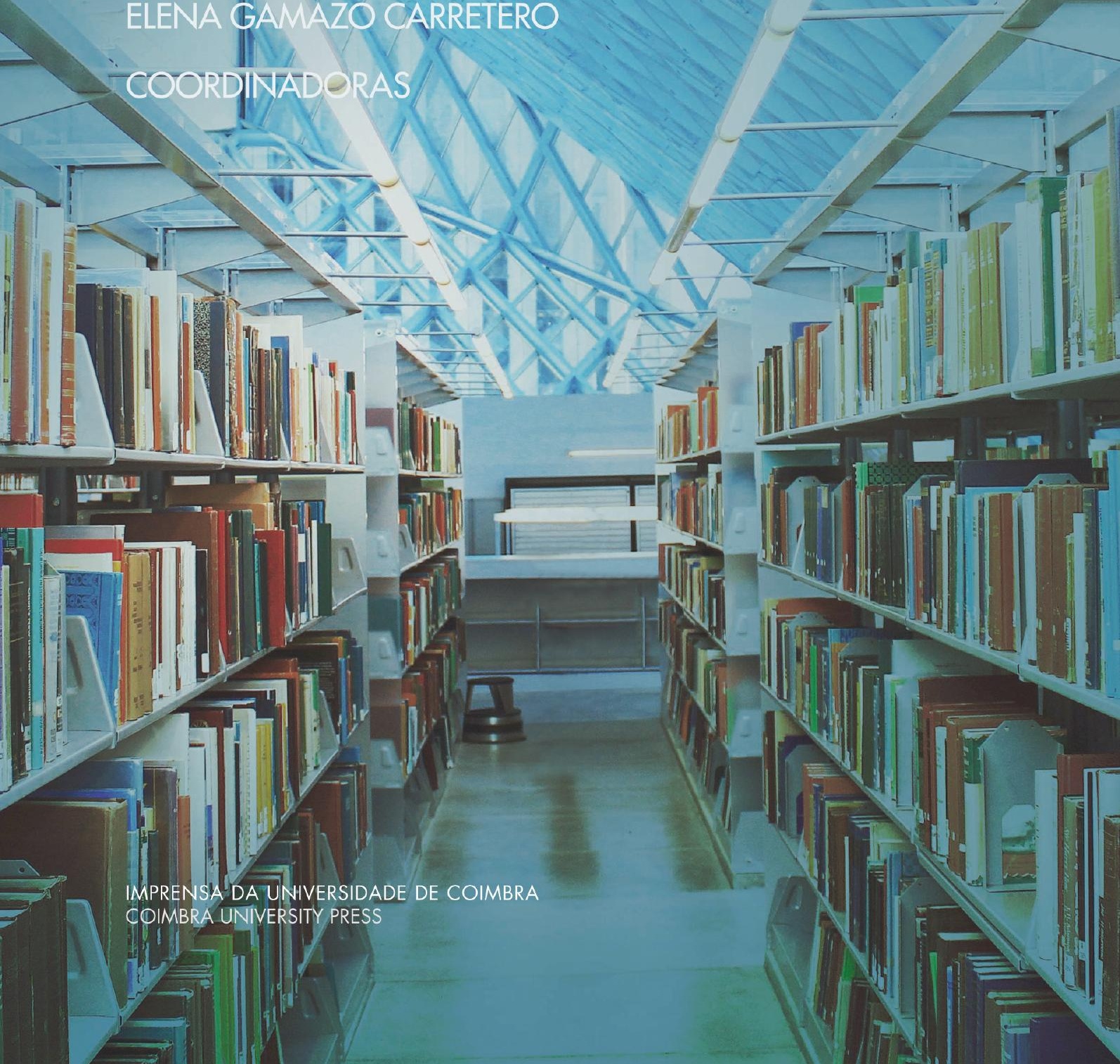




\title{
LAS UNIDADES LÉXICAS Y LA ENSEÑANZA DEL LÉXICOA EXTRANJEROS
}

\author{
Marta Higueras García \\ Instituto Cervantes
}

\begin{abstract}
In this paper, we help reflect on the units of analysis on which to base the teaching of vocabulary. To this, we start from the conviction that the teaching of foreign students lexicon has to focus on the study of lexical units and not be limited to words. So then after identify and explain the types of relevant teaching E/LE lexical units, present the advantages of teaching vocabulary from lexical units.
\end{abstract}

Keywords: learning vocabulary, word, lexical unit.

\section{RESUMEN}

En este trabajo pretendemos ayudar a reflexionar sobre las unidades de análisis en las que asentar la enseñanza del léxico. Para tal, partimos de la convicción de que la enseñanza del léxico a alumnos extranjeros ha de centrarse en el estudio de las unidades léxicas y no limitarse únicamente a palabras. Así pues, a continuación, tras 
delimitar y explicar los tipos de unidades léxicas relevantes para la enseñanza de $\mathrm{E} / \mathrm{LE}$, presentamos las ventajas de enseñar léxico a partir de unidades léxicas.

Palabras clave: aprendizaje del léxico, palabra, unidad léxica.

\section{INTRODUCCIÓN}

Entre los diferentes componentes de la enseñanza de una lengua extranjera, la enseñanza del léxico ocupa sin duda un lugar destacado. Tanto profesores como alumnos son conscientes de su utilidad y los primeros especialmente sienten la necesidad de incorporarlo en las clases, sin que resulte siempre fácil delimitar qué léxico enseñar, cuándo y cómo.

El presente trabajo tiene como objetivo principal ayudar a reflexionar sobre las unidades léxicas, es decir, acerca de las unidades de análisis sobre las que se debe basar la enseñanza del léxico; en primer lugar aparece una delimitación del concepto de unidad léxica y, en segundo, se desarrollan ampliamente los cuatro tipos de unidades léxicas que cabe considerar desde una perspectiva didáctica, con una especial atención a los tipos de expresiones idiomáticas. Por último, se analizan las ventajas de concebir la enseñanza del léxico a extranjeros basada en unidades léxicas y no en palabras.

\section{Delimitación de conceptos}

Nuestro punto de partida es que la enseñanza del léxico a extranjeros no debe descansar sólo en palabras, sino en unidades léxicas, un concepto más amplio que incluye tanto lo que tradicionalmente entendemos por palabras, como otras combinaciones - más o menos 
fijas -, que estudiaremos a lo largo del presente trabajo: las combinaciones sintagmáticas, las expresiones idiomáticas y las expresiones institucionalizadas.

Limitarse únicamente a enseñar palabras sería comparable a restringir la enseñanza de la gramática a categorías como el nombre, el adjetivo o el verbo sin tener en cuenta unidades mayores como la oración o el texto o, por ejemplo, concluir que la arquitectura es el estudio de los ladrillos con los que se hace una casa.

Evidentemente las palabras forman parte de cualquier estudio del léxico, pero no parece ser la unidad adecuada para la enseñanza de léxico a extranjeros, al dejar fuera ciertas combinaciones que requieren una especial atención por parte del aprendiente por ser idiosincrásicas de cada lengua y, en algunas ocasiones, idiomáticas.

A continuación ofrecemos una propuesta personal que incluye todos los tipos de unidades léxicas que deben enseñar los profesores de lengua extranjera. Los cuatro tipos de unidades léxicas contemplados son:

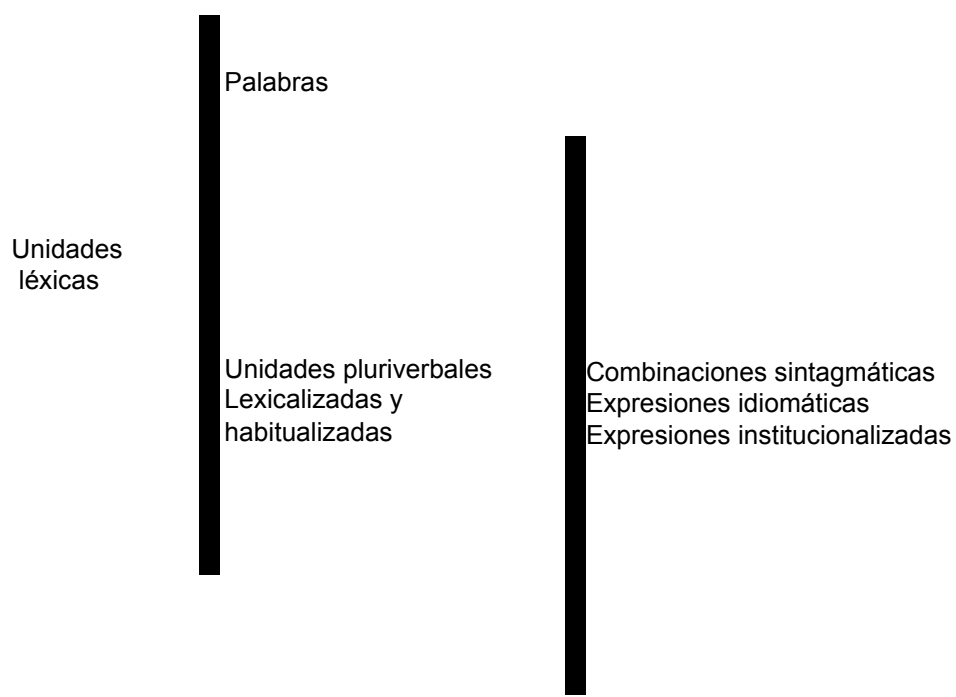


La incorporación del término "unidades pluriverbales lexicalizadas y habitualizadas" nos parece acertada para dar cuenta de las unidades léxicas que constan de más de una palabra (pluriverbales), que se diferencian de las combinaciones de palabras precisamente en que hay cierta cohesión interna entre ellas (lexicalizadas), y en que son la combinación más usual empleada por un nativo en un contexto determinado (habitualizadas).

\section{Las combinaciones sintagmáticas}

Entendemos por combinación sintagmática una unidad léxica formada por dos lexemas, que tiene un sentido unitario, semánticamente transparente, con cierta estabilidad y cohesión interna, que no equivale a un elemento oracional desde el punto de vista sintáctico ni morfológico y que sirve para dar cuenta de las restricciones combinatorias de las palabras desde el punto de vista semántico.

Si analizamos paso a paso cada uno de los semas contenidos en esta definición, lo primero que podemos constatar es que la combinación sintagmática es un tipo de unidad léxica y no un tipo de relación semántica, como en principio sugirió el término "colocación"1 o "solidaridad léxica" ${ }^{2}$, de los que es heredera, y

\footnotetext{
${ }^{1}$ Stefan Ettinger (1982) desde una perspectiva lexicográfica define las colocaciones como: «la tendencia sintáctico-semántica de las palabras aisladas de una lengua a adoptar tan sólo un número limitado de combinaciones de otras palabras». A continuación señala que esas combinaciones se pueden deber a motivos extralingüísticos (por ejemplo, nuestro conocimiento del mundo parece descartar *aballo rojo) o a criterios semánticos y sintácticos. Volveremos sobre esta idea ya que será en este último caso en el que se produzcan más interferencias con la lengua materna; consecuentemente, el profesor de una lengua extranjera debe, centrarse en las que son idiosincrásicas de la lengua objeto.

${ }^{2}$ El término se debe a Coseriu (1977), quien lo define del siguiente modo: «La solidaridad es la relación entre dos lexemas pertenecientes a campos distintos de los que uno está comprendido en parte o en su totalidad en el otro, como rasgo distintivo (sema) que limita su combinabilidad. Distinguimos tres tipos de solidaridad: afinidad, selección e implicación».
} 
de ahí que prefiramos denominarla "combinación sintagmática" para diferenciarlas.

La primera característica pues, es que es una unidad léxica formada por dos lexemas, aunque también podríamos considerar que los casos de "régimen" son otro tipo de combinaciones sintagmáticas de tipo gramatical, como hacen Benson, Benson \& Ilson $^{3}$ (1986).

En segundo lugar, hemos afirmado que la combinación sintagmática tiene un sentido unitario, de ahí que semánticamente se pueda considerar una unidad. Esta idea es especialmente importante desde la perspectiva de la didáctica del léxico a extranjeros: por ejemplo, si en un texto aparecieran estas dos frases: Los empresarios han convocado una reunión para finales de semana o El cazador le tendió una trampa, no tendría sentido centrar la atención del alumno en palabras como convocar o tender, sino en las unidades léxicas enteras: convocar una reunión o tender una trampa, ya que a la hora de explicar el significado de estas dos palabras - convocar y tender - sería difícil hacerlo sin recurrir a los matices que adquieren al combinarse con sus complementos respectivos.

En tercer lugar, cabe notar que las combinaciones sintagmáticas son semánticamente transparentes, es decir, que su significado es la suma de los significados de las palabras que la integran y ésta será una de las características que las distingan de las expresiones idiomáticas.

Hemos señalado, en cuarto lugar, que la combinación sintagmática posee cierta estabilidad y cohesión interna que se manifiesta, por poner un ejemplo, en la concordancia en género y número cuando aparecen sustantivos y adjetivos. Hablamos de cierta estabilidad

3 Para estos autores, falta de, fiel a, avergonzarse de... serían ejemplos de combinaciones sintagmáticas gramaticales, frente a ejemplos como situación delicada, rogar encarecidamente, rayar un disco, coger un avión, poner una multa, problema gordo... que serían casos de combinaciones sintagmáticas léxicas. 
para diferenciarlas de las combinaciones libres por un lado y de las expresiones idiomáticas por otro, ya que estas últimas están casi totalmente fijadas en la lengua y admiten muy pocas variaciones. La estabilidad y cohesión relativa que caracteriza a las combinaciones sintagmáticas permite la inclusión de modificadores, la transformación a pasivas y los cambios de gradación del adjetivo por ejemplo, pero no la alteración del orden (excepto la del adjetivo, que es frecuente en español), ni la sustitución por sinónimos. Obsérvense estos ejemplos:
Ej.: situación muy delicada/situación un poco delicada
Ej.: el avión fue cogido.../la multa fue puesta por el policía...
Ej.: problema gordísimo/situación delicadísima
$\mathrm{Ej} .:$ *el avión coger/*encarecidamente rogar
$\mathrm{Ej} .:$ "problema grueso

También es curioso señalar que no hay la misma cohesión o grado de implicación en una dirección que en otra; por ejemplo, relinchar implica la aparición de un sujeto caballo, pero no a la inversa, puesto que caballo se combina con otros verbos, como saltar, comer, dormir, correr, etc.

En quinto lugar, hemos puesto de manifiesto en la definición de combinación sintagmática que no equivale a un elemento oracional desde el punto de vista sintáctico ni morfológico, es decir que no desempeña la función de un nombre o un adjetivo o un adverbio, puesto que son un tipo de relación que se crea desde el punto de vista semántico y no sintáctico. Volveremos sobre este punto para diferenciarlas de las palabras compuestas.

Por último, hemos concluido diciendo que las combinaciones sintagmáticas sirven para dar cuenta de las restricciones combinatorias de las palabras, hecho crucial en el aprendizaje del léxico como lengua extranjera. 


\subsection{Tipos de combinaciones sintagmáticas}

Se pueden encontrar distintos tipos de clasificaciones según el punto de vista que se adopte. Ya hemos visto que algunos autores las dividen en dos grupos, las léxicas y las gramaticales, teniendo en cuenta el tipo de palabras que la forman.

Otro criterio que se podría tener en cuenta es el origen de las combinaciones sintagmáticas, lo cual es útil por sus implicaciones didácticas. De este modo, distinguimos dos grupos: las que están determinadas por el conocimiento del mundo y las determinadas por la lengua.

En algunos casos, las combinaciones sintagmáticas tienen un alcance único, es decir que la aparición de un término implica la utilización de otro, porque los rasgos sémicos incluidos en esa palabra, asociados a nuestro conocimiento del mundo exigen esa relación; ejemplos de ello serían: talar un árbol, el perro ladra o la rana croa.

Esta idea ya estaba apuntada en Coseriu (1977) y es la responsable de que podamos desviarnos voluntariamente de la norma para crear asociaciones poéticas, como por ejemplo: Las piedras lloran su ausencia o El caballo rojo de pasión galopaba por los valles.

Por otra parte, en todas las lenguas hay también muchas combinaciones idiosincrásicas que posibilitan unas combinaciones e imposibilitan otras, independientemente de las realidades extralingüísticas a las que se refieren (compárese chica morena frente a *chica marrón). A modo de ejemplo diremos que en español el deporte se hace, pero no se realiza, en español la lotería nos toca, pero en inglés se gana, en español se hace una pregunta y en francés se pone, en español se tienen cosquillas y en italiano se sufren, en español se tienen niños y en árabe se hacen..., por apuntar algunos de los innumerables ejemplos que podríamos citar. 
En este sentido, seguimos la línea de Saussure (1916) cuando distinguía entre combinaciones libres, que son del dominio del habla, entendiendo por ésta la utilización del código por parte del hablante con la finalidad de expresar su pensamiento personal, frente a las combinaciones no libres, que vienen determinadas por la lengua ${ }^{4}$.

\subsection{Distinción entre combinaciones sintagmáticas y palabras compuestas}

Al estar formadas las combinaciones sintagmáticas por dos lexemas es preciso no confundirlas con las palabras compuestas. Se aprecian algunas características comunes: el hecho de ser ambas unidades una combinación estable de lexemas y que formen una unidad con un significado unitario nuevo. Citamos la definición de "compuesto" del Diccionario de Lingüística (1979):

Se llama palabra compuesta a una palabra que contiene dos, o más de dos, morfemas léxicos y que corresponde a una unidad significativa: coliflor, portafolios, son palabras compuestas.

Sin embargo, las diferencias que observamos entre los dos conceptos son muchas:

${ }^{4}$ F. de Saussure ofrece dos tipos de ejemplos, según se cita en J. Dubois et al. (1979): A) á quoi bon?, allons donc!, a forcé de.pas n'est besoin..., ¡Vamos, hombre!, janda ya!, a fuerza de, a santo de qué, no hay por qué... "Estos giros no pueden ser improvisados ya que son suministrados por la tradición»; B) El derivado francés inécorable (indecorable) se ha fabricado según el principio de la cuarta proporción, a partir de décorer, siguiendo el modelo pardonner/impardonnable. Saussure ve aquí una combinación de la lengua, no del habla. Es decir, que todo neologismo proviene del mecanismo de la lengua. 
a. El compuesto pertenece a una categoría gramatical y la combinación sintagmática no, puesto que es una unidad semántica formada por la suma de dos categorías:

\begin{tabular}{|l|l|l|}
\cline { 2 - 3 } \multicolumn{1}{c|}{} & Compuestos & $\begin{array}{l}\text { Combinaciones } \\
\text { sintagmáticas }\end{array}$ \\
\hline$(\mathrm{V}+\mathrm{CD})$ & Sacacorchos (sust.) & Convocar una reunión \\
\hline (N + ADJ) & Aguardiente (sust.) & Fruta madura \\
\hline
\end{tabular}

b. Se comportan de distinta manera frente a la variación de número. Para formar el plural de una combinación sintagmática es preciso que vayan en plural las dos palabras que la forman: Ej.: fruta madura/"frutas madura/"fruta maduras. Sin embargo, como señalan Alcina \& Blecua (1991) en la formación del plural de los nombres compuestos influye el grado de cohesión alcanzado por los componentes. Cuando los elementos tienen una gran cohesión, si admiten el plural, lo forman sobre el último componente; si su cohesión no es completa, lo forma el primer constituyente o ambos, de ahí que coexistan: guardias civiles y guardiaciviles.

Continúan estos autores (1991) de este modo:

Los compuestos por dos nombres, uno en función sustantiva y otro en función adjetiva, son los que más fácilmente se lexicalizan y forman el plural según el último miembro componente. Ej.: bocamangas, salvoconductos, bocacalles, ferrocarriles, parabrisas, agridulces, padrenuestros, vanaglorias....

Por último, los compuestos formados por un verbo más un sustantivo forman el plural flexionando el sustantivo o quedan invariables. Ej.: guardarropas, salvamanteles, sacacorchos, quitamanchas. 
Cuando el último componente es el verbo, se mantienen invariables. Ej.: haz- merreír, quitaipón.

c. Se comportan de distinta manera frente a la variación de género. En las combinaciones sintagmáticas en las que aparecen nombres $\mathrm{y}$ adjetivos todos deben concordar en género, mientras que en los compuestos es posible que uno sea masculino y otro femenino, pues lo que importa es el género del compuesto resultante.

Ej.: la fruta madura/*la fruta maduro

Frente a:

Ej.: coche $(m)+$. cama $(f)=.>$ el coche cama

d. En el compuesto hay un proceso de lexicalización en un grado mayor que en las combinaciones sintagmáticas; este hecho se refleja en varios aspectos:

- La mayoría de los compuestos se escriben gráficamente en una sola palabra y las combinaciones sintagmáticas no.

- Algunas palabras se han modificado al formar parte de un compuesto (agridulce, ojinegro...).

- Los verbos no se pueden conjugar en un compuesto, pero sí en una combinación sintagmática: compárense voy a convocar una reunión/convoqué una reunión/convocaré una reunión frente a sacacorchos/*saquécorchos.

- Como señalaron Hernanz \& Brucart (1987) el segundo elemento nominal de un compuesto no puede aparecer dotado de un especificador o de un complemento propio: *coche cama comodísima, "pez dos espadas... y nosotros constatamos que esta restricción no afecta a las combinaciones sintagmáticas: fruta madura/fruta muy madura, convocar una reunión/ convocar urgentemente una reunión. 


\section{Expresiones idiomáticas}

Respecto al segundo grupo que denominamos "expresiones idiomáticas", las definimos como las expresiones fijas de dos o más palabras que comparten las características de estabilidad e idiomaticidad (determinada por la lengua y no por el conocimiento del mundo) y que deben ser completadas por otras palabras para poder formar una oración.

Zuloaga (1980) define la idiomaticidad en los siguientes términos:

El rasgo semántico propio de ciertas construcciones lingüísticas fijas, cuyo sentido no puede establecerse a partir de los significados de sus elementos componentes ni del de su combinación.

La estabilidad la entendemos en el sentido que resumen Varela \& Kubarth (1994) y es la que imposibilita en la mayoría de los casos, aunque hay excepciones, variaciones como las siguientes (los ejemplos son de los propios autores):

- Cambio de orden

Ej.: Común y corriente

*Corriente y común

- Alteración en el número de elementos

Ej.: Con mil amores haré lo que me pides

*Con amores haré lo que me pides

- Conversión a pasivas

Ej.: Donde Cristo dio las tres voces

*Donde fueron dadas las tres voces por Cristo...

- Derivaciones u otros procesos de formación de palabras Ej.: Llueve sobre mojado

*Lluvia sobre mojado 
- Sustitución por sinónimos

Ej.: ¡Se acabó lo que se daba!

*Se terminó lo que se daba!

- Cambios en la gradación del adjetivo

Ej.: Ser una buena alhaja

*Ser una buenísima alhaja

Dentro de las expresiones idiomáticas consideramos los siguientes tipos: locuciones, clichés, comparaciones fijadas, timos o muletillas, frases hechas y complejos fraseológicos con casillas vacías.

\subsection{Locuciones}

Aceptamos la definición de Sevilla \& Arroyo (1993) y discrepamos en los tipos de locuciones que había señalado Casares (1992) (reim- $^{5}$ presión); así, entendemos por locución la expresión pluriverbal fija e idiomática que no forma una oración cabal y funciona como un elemento oracional.

5 Partiendo de la definición del DRAE y modificando algunos aspectos, J. Casares propuso la siguiente definición de locución: "Combinación estable de dos o más términos, que funciona como elemento oracional y cuyo sentido unitario consabido no se justifica, sin más, como una suma del significado normal de los componentes».

Para Casares las locuciones tienen tres características: en primer lugar, la inalterabilidad, es decir que las palabras que la forman están vinculadas de un modo estable; en segundo, que los hablantes la conciben como una fórmula estereotipada de sentido unitario y, por último, que puede constituir una oración cabal (a diferencia de lo que señala la definición del DRAE). Algunos de los ejemplos citados son: Con tal de que, ¡Ancha es Castilla!', que no tiene donde caerse muerto, lengua de gato, coser y cantar, etc.

Según su opinión, las locuciones forman dos grandes grupos desde el punto de vista morfológico y funcional: significantes, integradas por voces con contenido semántico y locuciones conexivas, las formadas por partículas vacías de contenido semántico y que sirven de enlace.

Las locuciones significantes pueden ser nominales, adjetivales, verbales, participiales, adverbiales, pronominales y exclamativas, según cumplan la función de un nombre, adjetivo, verbo, etc.

Por otra parte, las locuciones conexivas también se dividen en dos grupos: las conjuntivas y prepositivas, en función de que sirvan de enlace de oraciones o sintagmas respectivamente. 
Hemos observado que el grupo que denominamos "locuciones" es bastante heterogéneo, puesto que en algunas de ellas se pueden intercalar otras palabras, los verbos se pueden conjugar e incluso se admiten ciertas variaciones y en otros tipos de locuciones no. Compárense estos ejemplos:

Ej.: - pasárselo bien/pasárselo en grande/pasárselo bomba... - meter la pata/he metido la patita hasta el fondo/meter un poco la pata...

Sin embargo, en las locuciones prepositivas, conjuntivas y adverbiales estos cambios no se toleran, por lo que estarían más cerca de la zona fronteriza con las frases hechas:

- a tontas y a locas/*a muy tontas y muy locas/*a locas $y$ a tontas

- con tal de que/*con tales de que

- en efecto/*en muy efecto

- por encima de/*por encimita de

- a través de/*través de

Muchos de los ejemplos que Casares califica de locuciones nominales son para nosotros palabras compuestas o combinaciones sintagmáticas: coche cama, falda pantalón, ciudad jardín, café bar o simplemente dos nombres en aposición: Hotel Victoria, Instituto Cervantes. Como podemos observar, ninguno de estos ejemplos cumple el criterio de idiomaticidad, que para nosotros es básico para diferenciar las expresiones idiomáticas de las combinaciones sintagmáticas.

Respecto a los ejemplos que propone Casares de locuciones adjetivas, bien podrían considerarse frases hechas, puesto que no es posible modificar ninguno de sus elementos: 
Ej.: de rompe y rasga/"de rasga y rompe

de chicha y nabo/*de carne y nabo

de órdago/*de envite

Donde discrepamos totalmente es en el caso de las locuciones verbales, acerca de las cuales Casares (1992) reconoce que "todas ellas ofrecen el aspecto de una oración, que puede ser transitiva, intransitiva o predicativa». Esta afirmación iría en contra de la definición que hemos propuesto de expresión idiomática, pues habíamos afirmado que las locuciones funcionan como un elemento oracional.

Nuestra clasificación de locuciones incluye los siguientes tipos: locuciones conjuntivas, locuciones prepositivas, locuciones adverbiales, locuciones predicativas, locuciones atributivas, locuciones nominales y locuciones adjetivas.

Las locuciones conjuntivas equivalen a una conjunción y son muy fijas, no admiten variación: con tal de que, a pesar de que...

Las locuciones prepositivas equivalen a una preposición y tampoco admiten variaciones: en pos de, a través de...

Las locuciones adverbiales equivalen a un adverbio, admiten pocas variaciones y son un grupo muy numeroso: de mañana (muy de mañana), en efecto, por supuesto (por supuestísimo), a oscuras...

Las locuciones predicativas equivalen a un predicado, es decir, a un verbo no copulativo más los complementos que precise. Preferimos este término a verbales, porque no siempre equivalen a un verbo sino a todo un predicado: pasárselo bomba, tomar el pelo, meter la pata...

Las locuciones atributivas equivalen a un verbo copulativo o semipredicativo y su atributo: estar sin blanca, estar verde, ser un viejo verde, etc.

Estos dos últimos tipos de locuciones - predicativas y atributivas admiten cambios de tiempo, persona... en el verbo, hecho que las diferencia de las frases hechas, en las que el verbo no se flexiona. 
Por otra parte, también son distintas de las combinaciones sintagmáticas, puesto que estas locuciones son semánticamente opacas y aquellas eran transparentes.

Las locuciones nominales equivalen a un nombre y suelen presentar la estructura N + ADJ o N + SPrep. Se diferencian de las combinaciones sintagmáticas en que son semánticamente opacas y admiten menos variaciones que aquellas: letra de cambio, guerra fría, mercado negro, cabeza de turco, etc.

Las locuciones adjetivas equivalen a un adjetivo: de rompe y rasga, de palabra, de fiar, de alto standing, etc.

\subsection{Clichés, comparaciones fijadas, frases hechas y timos o muletillas}

Coincidimos con Sevilla \& Arroyo (1993) en las definiciones que han propuesto de estos términos. El cliché lo definen como un sintagma nominal, aspecto que lo diferencia de otras expresiones idiomáticas, que contiene una metáfora que era expresiva en sus orígenes pero que se ha trivializado y codificado por su uso frecuente. Ej.: Las perlas de su boca, el astro de la noche...

Las comparaciones fijadas se parecen a las locuciones verbales en que tienen un verbo conjugado, pero se distinguen por su estructura claramente comparativa. Ej.: Ser blanco como la nieve, ser más terco que una mula, dormir como un tronco.

Las frases hechas las presentan como una expresión que

se inserta en el discurso como una pieza única y que no ofrece posibilidades de cambios en ninguno de sus elementos ni de inserción de otros.

Ej.: Otro gallo me cantara 
Esta precisión nos parece pertinente porque las distingue de las locuciones predicativas y atributivas en las que el verbo se conjuga y puede aparecer modificado por circunstanciales, por ejemplo. También las diferencian de las frases proverbiales $^{6}$, ya que las frases hechas no tienen el carácter moralizante de las frases proverbiales, como puede observarse en estos ejemplos: donde Cristo dio las tres voces, en el quinto pino, el día que las ranas críen pelo...

Por último, los timos o muletillas son juegos de palabras con rima interna, cuyo sentido está basado en los efectos fonéticos. La primera parte es generalmente un verbo y alude a una realidad inmediata, con la que tanto el hablante como el oyente están familiarizados; la segunda parte suele ser un nombre propio que rima con el anterior. Ej.: estéis listo Calixto; de eso nada, monada; una y no más, Santo Tomás...

\subsection{Complejos fraseológicos con casillas vacías}

Compartimos la definición que proponen Varela \& Kubarth (1994) en el prólogo de su diccionario fraseológico:

\footnotetext{
${ }^{6}$ El concepto de "frase proverbial" está para Casares (1992) a caballo entre las locuciones y los refranes, por lo tanto una buena manera de definirlo es señalar sus diferencias con unas y otros. Este autor entiende "proverbial" del siguiente modo: «algo que tiene una tradición de ejemplaridad por consenso de una comunidad lingüística; [...] es siempre algo que se dijo o se escribió y su uso en la lengua tiene el carácter de una cita, de algo que se trae a cuento ante una situación que en algún modo se asemeja a la que dio origen al dicho. Su valor expresivo no está en las imágenes que pueda contener, cosa que es esencial en las locuciones significantes, sino en el paralelismo que se establece entre el momento actual y otro pretérito, evocado con determinadas palabras». Ej.: en el mundo ha habido muchos casos de paciencia, pero en la fraseología española sólo se ha consolidado unida al santo Job; respecto a las guerras, ha perdurado el recuerdo de Troya (Alli fue Troya), etc.

Por último, cabe señalar que las frases proverbiales son privativas de los pueblos en que nacieron, no se pueden emplear en otros contextos culturales.
} 
Son construcciones que contienen una estructura idiomática estable, pero que ofrecen una o más casillas vacías que pueden ser rellenadas solamente por palabras pertenecientes a determinada categoría semántica o gramatical

Ej.: a ... (tiro, golpe, tortazo, puñetazo...) limpio

\section{Expresiones institucionalizadas}

En líneas generales, el concepto de "expresiones institucionalizadas" ("institutionalized expressions" para Lewis 1993) coincide con el de "expresiones" de Varela \& Kubarth (1994) que citamos a continuación, aunque a nosotros la elección del término "expresiones" no nos parece muy acertada, pues es demasiado general:

Se trata de secuencias que, en muchos casos, constituyen residuos de oraciones gramaticalmente completas y que aquí se encuentran reducidas a muy pocos elementos [...] y que contribuyen al buen funcionamiento de la comunicación o facilitan la interacción social y sólo dentro de éstas se comprende su estabilidad e idiomaticidad.

$\mathrm{Ej} .:$ dicho sea de paso, lo que oyes, yo que tú, que en paz descanse

Desde nuestro punto de vista forman parte del léxico, aunque están a caballo entre el léxico y la gramática. La idea de su inclusión como parte de la enseñanza del léxico la tomamos de Lewis (1993), pero indirectamente estaba ya formulada en el concepto de exponente defendido por el enfoque comunicativo de enseñanza de lenguas. 


\section{Consecuencias didácticas}

Una vez precisados los distintos tipos de unidades léxicas, pasamos a comentar las consecuencias didácticas de convertir la enseñanza del léxico en algo más que enseñar palabras.

La principal ventaja de enseñar unidades léxicas es que, al utilizar un concepto más amplio que la unidad palabra, ayudamos al alumno a combinarlas y favorecemos de este modo el proceso de aprendizaje y recuperación y mejoramos su competencia comunicativa.

En primer lugar, nos centraremos en las ventajas de enseñar combinaciones sintagmáticas, para lo cual citamos las opiniones de dos autores y las nuestras propias.

Lewis (1993) defiende que enseñar combinaciones sintagmáticas es decisivo porque ayuda a formar redes de significados entre palabras, con lo cual se favorece su aprendizaje y recuperación, ya que parece que así se almacenan las unidades léxicas en el lexicón.

Este tipo de información horizontal referente a la combinación de las palabras constituye una parte decisiva del Enfoque léxico, defendido por Michael Lewis (1993), que consiste en enseñar a segmentar en unidades significativas (chunking), ya que se basa en la creencia de que en la memoria no se almacenan palabras aisladas, sino unidades de significado más amplias. Esta es una estrategia que ayudará después al aprendiente a recuperar más fácilmente las unidades necesarias en una situación concreta ${ }^{7}$.

\footnotetext{
7 En este sentido Lewis parece hablar de lo que se ha denominado "significado estructural" frente al significada "léxico" (Simone, 1993), entendiendo por el primero el significado que queda tras la extracción de los morfemas léxicos, puesto que tiene que ver con estructuras, aunque sean vacías, preparadas para ser rellenadas por un conjunto de morfemas léxicos sintagmáticamente compatibles entre sí. Por ejemplo, en el enunciado el presentador ha anunciado al cantante, la estructura abstracta que obtendríamos al suprimir los morfemas léxicos sería: el_dor ha_do al__te.

El significado estructural de este enunciado se puede describir mediante proposiciones: a) el agente ha llevado la acción de___ar sobre el beneficiario; b) la
} 
Por otra parte, Howard (1988) añade otras ventajas de enseñar combinaciones sintagmáticas:

1. En función de la palabra con la que se combine, una palabra adquiere un significado específico: (los ejemplos son nuestros). $\mathrm{Ej} .:$ comida fuerte $=[$ intensidad de sabor $] ;$ persona fuerte $=$ [con fuerza física]; madera fuerte $=$ [resistente] .

2. Con las combinaciones sintagmáticas sabemos el alcance de una palabra, esto es, los grupos de palabras con los que se puede combinar. Ej.: regar $\longrightarrow$ el césped, plantas, flores y árboles.

3. Ayuda a comprender las metáforas. Cuando entendemos una metáfora como premonición de bielo es porque conocemos las combinaciones sintagmáticas normales de premonición, a saber, muerte, desastres, etc.

4. En algunos casos, la presencia de una palabra implica la aparición de la otra: es un caso extremo de alcance único. Ej.: el caballo relincha.

En este punto al profesor de lenguas extranjeras le surgirá la duda de qué combinaciones sintagmáticas debe enseñar, pues son miles las que existen en cada lengua. Como es de esperar, las combinaciones sintagmáticas que se derivan del conocimiento del mundo no es preciso enseñarlas, ya que son universales; sin embargo, las que no son equivalentes en L1 y L2, es decir las que son propias de cada lengua, crean muchos problemas y son las que fundamentalmente debemos enseñar, como demuestra el trabajo de Bahn (1993).

Desde el punto de vista de la comprensión, las combinaciones sintagmáticas no presentan muchas dificultades, puesto que, como señalamos en la definición, son transparentes; sin embargo, a la hora

acción se ha desarrollado en el pasado y está completamente terminada; c) tanto el agente como el beneficiario son numéricamente singulares. 
de producirlas surgen innumerables problemas, porque aparecen frecuentemente casos de interferencia de la lengua materna.

En segundo lugar, también las expresiones idiomáticas deben ocupar un papel destacado en la enseñanza del léxico a extranjeros $\mathrm{y}$, de todos los tipos señalados, ocuparán un papel privilegiado las frases hechas y, en menor media, las comparaciones fijadas. Al ser unidades idiomáticas, cuyo significado no se puede entender a pesar de conocerse el significado de las palabras que las integran, suponen una dificultad para el extranjero, tanto a la hora de comprenderlas como de producirlas.

Además, a este hecho hay que añadir una dificultad adicional que radica en que no siempre se puede encontrar un equivalente en la otra lengua. Sin embargo, a pesar de la dificultad que entrañan, por ejemplo la enseñanza de complejos fraseológicos con casillas vacías es muy útil para ayudar a segmentar adecuadamente en unidades léxicas y potenciar esta estrategia que ayudará a los aprendientes a entender fiases nunca oídas antes.

Por ejemplo, si enseñamos la siguiente estructura fraseológica: [hacer algo] en [expresión que denota una cantidad de tiempo corta], cuando el alumno se encuentre con ejemplos como los siguientes es muy posible que los entienda, gracias al contexto y al conocimiento de este complejo fraseológico. Ej.: en un pis pas, en un periquete, en un abrir y cerrar de ojos, en menos que canta un gallo, en un momento, etc.

Para concluir, también las expresiones institucionalizadas tienen un papel decisivo en la enseñanza de una lengua extranjera, puesto que su carácter pragmático deja clara la intención del hablante y su enseñanza sirve para agilizar las partes más rutinarias de la conversación y mejorar la competencia comunicativa de los alumnos.

Lo importante en lo que se refiere a su didáctica es que están fijadas por el contexto y por la intención del hablante y que los alumnos reconocen su carácter de unidad o fórmula, puesto que en sus lenguas maternas también se utilizan procedimientos parecidos. 


\section{B I B LIO G RA Fí A}

Alcina Franch, J. \& Blecua, J. M. (1991). Gramática española. Barcelona: Ariel.

Bahn, J. (1993). Lexical collocations, ELTJ, 7 y V47/I (56-63), Oxford: Oxford University Press.

Baylon, Ch. \& Fabre, P. (1994). Semántica. Barcelona: Paidós.

Cardona, G. R. (1991). Diccionario de Lingüística. Barcelona: Ariel.

Benson, M., Benson, M. \& Ilson, R. (1986). The BBI Combinatory Dictionary of english. Amsterdam: John Benjamins.

Carter, R. \& Mc. Carthy, M. (Eds.) (1988). Vocabulary and Language Teaching. London: Longman.

Casares, J. (1992). Introducción a la lexicografía moderna. Madrid: CSIC.

Coseriu, E. (1977). Principios de semántica estructural. Madrid: Gredos.

Coseriu, E. (1966). Structure lexicale et enseignement du vocabulaire, Actas $d u$ premier colloque international de linguistique appliquée (Annales de 1'est, Mémoire), 31 (27-40). Nancy.

Dubois, J. et al. (1979). Diccionario de Lingüística. Madrid: Alianza Editorial.

Forment Fernández, M. (1998). La didáctica de la fraseología ayer y hoy: del aprendizaje memorístico al agrupamiento en los repertorios de funciones comunicativas. In F. Moreno, M. Gil \& Alonso, K. (Coods.), La enseñanza del español como lengua extranjera: del pasado al futuro. Actas del VIII Congreso Internacional de ASELE, (339-347). Alcalá de Henares: Publicaciones de la Universidad de Alcalá.

García-Page, M. (1996). Problemas en el empleo de la fraseología española por hablantes extranjeros: la violación de restricciones. In M. Rueda, E. Prado, J. Lemen \& F. J. Grande (Eds.), Actas del VI Congreso Internacional de ASELE (155-162). León: Universidad de León.

Haensch, G., Wolf, L., Ettinger, S. \& Werner, R. (1982). La lexicografía. De la lingüística teórica a la lexicografía práctica. Madrid: Gredos.

Hernanz, M. L. \& Brucart, J. M. (1987). La sintaxis. 1. Principios teóricos. La oración simple. Madrid: Crítica.

Higueras García, M. (1996). Aprender y enseñar léxico. In L. Miquel \& Sans, N. (Coord.), Didáctica del español como lengua extranjera, 3, (111-126). Madrid: Colección Expolingua, Fundación Actilibre.

Higueras García, M. (1997). La importancia del componente idiomático en la enseñanza del léxico a extranjeros. Frecuencia L, 6 (15-19). Madrid: Edinumen.

Howard, J. (1988). Words and their meaning. New York: Longman.

Howard, J. (1988). Phraseology and second language proficiency, Applied Linguistics, $19,1,(24-44)$

Lennon, P. (1998). Approaches to the teaching of idiomatic language, IRAL, XXXVI/1, February, (11-30).

Lewis, M. (1993). The Lexical Approach. London: Language Teaching Publications.

Lyons, J. (1980). Semántica. Barcelona: Teide. 
Mc. Carthy, M. \& O'dell, F. (1994). English Vocabulary in Use. Cambridge: Cambridge University Press.

Mc. Carthy, M. (1990). Vocabulary. Oxford: Oxford University Press.

Moreno Cabrera, J. C. (1994). Curso universitario de lingüística general. Madrid: Síntesis.

Piñel, R. $M^{a}$. (1996). Fraseologismos modificados en publicidad: estudio comparado alemán-español, Frecuencia L, 4 (32-36). Madrid: Edinumen.

Sevilla Muñoz, J. \& Arroyo, A. (1993). La noción de "expresión idiomática» en francés y en español. Revista de Filología Francesa, 4, 247-261.

Saussure, F. De (1916). Curso de Lingüística general. Buenos Aires: Losada.

Simone, R. (1993). Fundamentos de Lingüística. Barcelona: Ariel Lingüística.

Varela, F. \& Kubarth, H. (1994). Diccionario fraseológico del español moderno. Madrid: Gredos.

Santos Gargallo, I., Bermejo Rubio, I., Derouiche, N., García Oliva, C., Higueras García, M. \& Varela Méndez, C. (1998). Bibliografía sobre enseñanza-aprendizaje de ELE. Publicaciones periódicas españolas (1983-1997): Anexo al número 43 de la revista Carabela. Madrid: SGEL.

Zuluaga, A. (1975). La fijación fraseológica, Thesaurus, 30, 53-61.

Zuluaga, A. (1980). Introducción al estudio de las expresiones fijas, Studia Románica et Lingüistica, 10. Berna: Francfort de Meno. 